\title{
Desempenho de cultivares de bananeiras na região do Médio Paranapanema, São Paulo ${ }^{1}$
}

\section{Performance of banana cultivars in Médio Paranapanema region, São Paulo state, Brazil}

\author{
Mara Rubia Camolesi²; Carmen Silvia Vieira Janeiro Neves ${ }^{3}$; \\ Adriana Novais Martins ${ }^{4 *}$; Eduardo Suguino ${ }^{5}$
}

\section{Resumo}

\begin{abstract}
A bananicultura é considerada como uma alternativa econômica para os produtores rurais da região do Médio Paranapanema, situada no Planalto Paulista. Este trabalho teve por objetivo identificar genótipos de bananeiras adaptadas às condições edafoclimáticas locais. $\mathrm{O}$ área experimental foi instalada no município de Palmital, SP, utilizando-se mudas micropropagadas de 9 cultivares, a saber: Caipira, Thap Maeo, Prata Zulu, Preciosa, Maravilha, PV 4253, Nanicão IAC 2001, Nanicão Jangada e Grande Naine. Foram avaliados parâmetros vegetativos e reprodutivos das plantas, além das características dos frutos. Os genótipos do subgrupo Cavendish apresentaram melhor comportamento vegetativo e produtivo, com destaque para a cultivar Nanicão Jangada que apresentou melhor comportamento para a maioria dos caracteres de produção avaliados. As cultivares Prata Zulu e Thap Maeo apresentaram comportamento semelhante a Nanicão IAC 2001, cultivada na região, e podem ser alternativas de cultivo já que apresentam resistência às sigatokas amarela e negra, principais doenças da cultura. Os genótipos Maravilha e PV 4253 apresentaram-se promissores para a região e necessitam ser melhor avaliadas em ciclos posteriores.
\end{abstract}

Palavras-chave: Banana, Musa sp., variedades, produtividade

\begin{abstract}
The banana crop is considered an economic alternative for farmers of the Médio Paranapanema region, in the Planalto Paulista, Brazil. This study aimed to identify banana plants genotypes adapted to local soil and climatic conditions. The experimental area was installed in the municipality of Palmital, SP, with plantlets of nine cultivars: Caipira, Thap Maeo, Prata Zulu, Preciosa, Maravilha, PV 4253, Nanicão IAC 2001, Nanicão Jangada and Grande Naine. Vegetative and reproductive parameters of the plants were evaluated, besides the characteristics of the fruits. The genotypes belonging to Cavendish subgroup showed better vegetative and productive results, with emphasis for 'Nanicao Jangada' that had the best performance for the most production characters evaluated. The cultivars Prata Zulu and Thap Maeo had results similar to Nanicão IAC 2001 cultivated in the region, and can be an alternative crop since they have resistance to yellow and black sigatokas, major diseases of the crop. The genotypes Maravilha and PV4253 showed to be promising for the region, and need to be evaluated further in subsequent cycles.

Key words: Banana, Musa sp., varieties, production
\end{abstract}

\footnotetext{
${ }^{1}$ Parte da Tese de Doutorado da primeira autora.

${ }^{2}$ Bióloga, Laboratório SGS, Santos, SP. E-mail: mrcamol@gmail.com

${ }^{3}$ Eng $^{\mathrm{a}}$ Agr $^{\mathrm{a}}$, Prof ${ }^{\mathrm{a}} \mathrm{Dr}^{\mathrm{a}}$, do Dept ${ }^{\mathrm{o}}$ de Agronomia, Universidade Estadual de Londrina, UEL, Londrina, PR. Bolsista CNPq. E-mail: csvjneve@uel.br

${ }^{4}$ Pesquisadora Científica, Eng ${ }^{\mathrm{a}}$ Agr $^{\mathrm{a}}$, Dra ${ }^{\mathrm{a}}$, Agência Paulista de Tecnologia dos Agronegócios, APTA Centro Oeste/DDD/SAA. Marília, SP. E-mail: adrianamartins@apta.sp.gov.br

${ }^{5}$ Pesquisador Científico, Eng ${ }^{\circ}$ Agr $^{\circ}$ Dr., APTA Centro Leste/DDD/SAA. Ribeirão Preto, SP. E-mail: esuguino@apta.sp.gov.br

* Autor para correspondência
} 


\section{Introdução}

No ano de 2009, a produção brasileira de banana foi de aproximadamente 7 milhões de toneladas, fazendo com que o país ocupasse posição de destaque na produção mundial desta fruta. São Paulo é o segundo estado que mais produz bananas, com 1,2 milhões de toneladas, sendo superado apenas pela Bahia, que produz 1,4 milhões de toneladas ao ano (AGRIANUAL, 2011).

A região do Médio Paranapanema, estado de São Paulo, cultiva banana há aproximadamente 20 anos. Em 2005 estimou-se na região uma área de produção de aproximadamente 2.500 ha, dos quais aproximadamente $95 \%$ eram cultivados com a variedade Maçã (FURLANETO et al., 2005; FURLANETO et al., 2007), no entanto o plantio desta variedade está se tornando inviável devido à presença do mal do Panamá na região.

A introdução de genótipos resistentes nestas áreas tem sido o método utilizado para contornar o problema e os genótipos, do subgrupo Cavendish, como as cultivares Grande Naine e Nanicão, são consideradas uma alternativa para a bananicultura da região (CORDEIRO; MATOS, 2000a; 2000b). Além destes, cultivares com características agronômicas interessantes, como a resistência à doença Sigatoka Negra, estão disponíveis (OLIVEIRA et al., 2008; LEDO et al., 2008).

Frente ao exposto, o objetivo do trabalho foi avaliar o comportamento agronômico de cultivares de bananeiras no município de Palmital, região do Médio Paranapanema, estado de São Paulo.

\section{Material e Métodos}

O experimento foi conduzido no município de Palmital, região do Médio Paranapanema, estado de São Paulo, com latitude $22^{\circ} 46^{\prime} 60$ S, longitude $50^{\circ} 12^{\prime} 0 \mathrm{~W}$ e altitude de 547 metros. O clima da região apresenta verão quente, sem estação seca de inverno (Cfa, segundo a classificação climática de Köeppen).
Foram avaliadas as cultivares Nanicão IAC 2001, Nanicão Jangada, Grande Naine, Caipira, Thap Maeo, Preciosa, Maravilha, Prata Zulu e PV4253 (genótipo) no período de 2006 a 2008. As cultivares Grande Naine e Nanicão Jangada foram utilizados como testemunhas por serem as mais cultivadas na região, em plantios de variedades do subgrupo Cavendish.

As mudas das cultivares Caipira, Thap Maeo, Prata Zulu, Preciosa, Maravilha e do genótipo PV4253 foram cedidas pela EMBRAPA Mandioca e Fruticultura Tropical - Empresa Brasileira de Pesquisa Agropecuária, e as mudas das cultivares Nanicão IAC 2001, Nanicão Jangada e Grande Naine foram cedidas por agricultores da região e micropropagadas no "Laboratório de Cultivo in vitro de Espécies Ornamentais e Frutíferas" da ADR-Biomavale, Assis - SP.

As mudas foram aclimatadas em tubetes de polipropileno com dimensões de $5 \mathrm{~cm}$ de diâmetro x $13 \mathrm{~cm}$ de altura e com 5 estrias, utilizando-se o substrato Plantmax ${ }^{\mathrm{TM}}$. Após 30 dias, as mudas foram transplantadas para laminados plásticos de $25 \times 25 \mathrm{~cm}$, com $0,1 \mathrm{~mm}$ de espessura, preenchidos com o substrato Plantmax ${ }^{\mathrm{TM}}$ e irrigadas uma vez por dia. As mudas foram levadas ao campo quando apresentaram 4 a 6 folhas, completamente desenvolvidas.

O plantio ocorreu em outubro de 2006 em uma área cedida por um produtor da região e durante a condução do experimento as plantas receberam os mesmos tratos culturais praticados a todas as bananeiras das áreas de produção, que por sua vez seguiram as recomendações técnicas para a cultura. O local utilizado é caracterizado por solo do tipo Latossolo Vermelho distrófico e as mudas foram plantadas em covas de $0,40 \mathrm{~m}$ nas três dimensões (comprimento, largura e altura) com espaçamento de 3,0 m x 3,0 m. O experimento foi instalado em blocos ao acaso com oito tratamentos (cultivares), quatro repetições e seis plantas por parcela, com bordadura dupla da cultivar Grande Naine. 
Devido à ocorrência de seca intensa logo após o plantio e fortes ventos durante a fase deflorescimento, em 2007, houve o tombamento de algumas plantas, e o desenvolvimento das bananeiras foi muito afetado, o que poderia comprometer os resultados. Por este motivo, optou-se por realizar uma poda drástica, cortando-se as plantas matrizes ao nível do solo, sendo mantidos os perfilhos. Os caracteres vegetativos foram avaliados em dois períodos: do plantio (outubro de 2006) até a poda da plantamatriz, (novembro de 2007) chamado ano 2006/07; e da poda da planta matriz até o florescimento do perfilho (outubro de 2008) chamado de ano 2007/08. A produção foi avaliada no ano de 2007/08.
Durante o ciclo da cultura, foram registrados os dados de pluviosidade $(\mathrm{mm})$ e de temperatura máxima e mínima $\left({ }^{\circ} \mathrm{C}\right)$, através do Sistema CIIAGRO/IAC (Centro Integrado de Informações Agrometeorológicas do Instituto Agronômico de Campinas) (Figura 1). Durante o período compreendido entre o plantio das mudas (outubro/2006) e a colheita dos cachos (outubro/2008), a temperatura média foi de $23,1^{\circ} \mathrm{C}$, variando entre $17,1^{\circ} \mathrm{C}$ (média das mínimas) e $29,1^{\circ} \mathrm{C}$ (média das máximas). O total de chuvas no período foi de $2.788 \mathrm{~mm}$ (CIIAGRO, 2011).

Figura 1. Dados de Precipitação total (mm) e média das temperaturas máxima e mínima $\left({ }^{\circ} \mathrm{C}\right)$, por mês, para o período de ocorrência do experimento em Palmital, estado de São Paulo, 2006/07 e 2007/08.

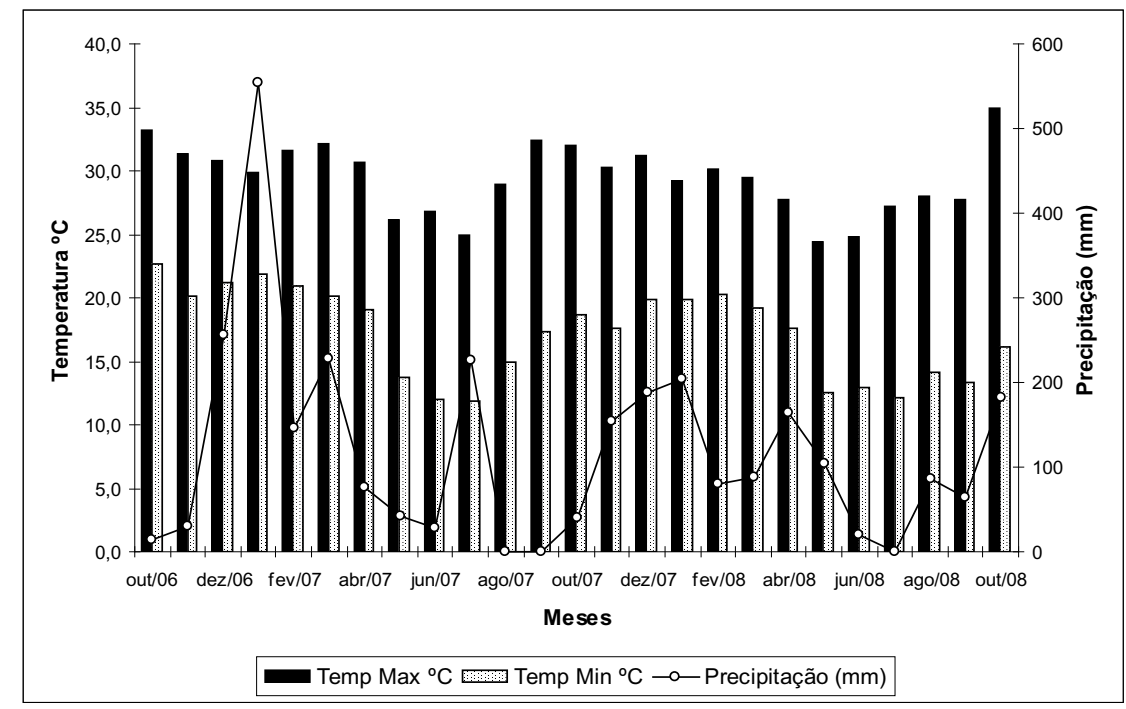

Fonte: CIIAGRO (2011).

Foram avaliados os caracteres vegetativos: circunferência do pseudocaule a $30 \mathrm{~cm}$ do solo (m), número de folhas vivas na época do florescimento da planta matriz (2006/07) e na colheita do primeiro perfilho (2007/08), altura de planta (m) e número de perfilhos. Não foi realizado desbaste dos perfilhos visto que um dos objetivos era avaliar a capacidade de perfilhamento.

Os caracteres de produção foram avaliados no ano de 2007/08: massa do cacho (kg), massa do engaço $(\mathrm{kg})$, massa das pencas $(\mathrm{kg})$, massa da $2^{\mathrm{a}}$ penca $(\mathrm{kg})$, número de pencas/cacho, número de frutos/cacho, número de frutos/penca, número de frutos da $2^{\text {a }}$ penca, diâmetro externo dos frutos na $2^{a}$ penca $(\mathrm{mm})$, espessura de casca de fruto da $2^{\circ}$ penca $(\mathrm{mm})$, comprimento de fruto da $2^{\mathrm{a}}$ penca $(\mathrm{cm})$ e massa de fruto na $2^{\mathrm{a}}$ penca $(\mathrm{g})$. Os caracteres de diâmetro, espessura, comprimento e massa dos frutos foram mensurados utilizando-se seis frutos da segunda penca, posicionados na região central desta (DONATO et al., 2006). 
Os dados foram submetidos à análise de variância complementada pelo teste de Scott-Knott $(\mathrm{p}<0,05)$ para agrupamento de médias.

\section{Resultados e Discussão}

Para os caracteres vegetativos das cultivares avaliadas (Tabela 1), a circunferência do pseudocaule variou entre $0,47 \mathrm{~m}$ e $0,69 \mathrm{~m}$ no ciclo de 2006/07 e entre 0,52 e $0,76 \mathrm{~m}$ no ciclo 2007/08, apresentando comportamento diferenciado entre as cultivares nos dois anos de avaliação. Para o ciclo 2006/2007 foram observados três grupos, que diferiram estatisticamente entre si, sendo que a circunferência foi maior para as cultivares PV 4253, Maravilha, Preciosa, Nanicão IAC 2001 e Grande Naine, seguido pelo grupo das cultivares Thap Maeo e Nanicão Jangada. A cultivar Caipira apresentou o menor valor de circunferência do pseudocaule da planta-mãe. Para o ciclo 2007/08 também foram observados três grupos para circunferência, sendo que o maior valor foi observado para a cultivar Maravilha, seguido pelo grupo formado pelas cultivares Nanicão IAC 2001, Grande Naine, Preciosa, PV 4253 e Nanicão Jangada. As cultivares Thap Maeo e Caipira apresentaram os menores valores deste parâmetro. Observando estes dados, podemos verificar que as cultivares Maravilha, com maior crescimento do pseudocaule, Nanicão Jangada, do grupo intermediário, e Caipira, com menor crescimento, mantiveram as mesmas características de desenvolvimento do ano anterior enquanto todas as outras cultivares mostraram, no segundo ano, um desenvolvimento inferior ao apresentado na primeira avaliação, mostrando que estas variedades podem ter sofrido influência das características regionais.

Tabela 1. Médias de circunferência do pseudocaule $(\mathrm{cm})$, número de folhas vivas, altura de plantas $(\mathrm{m})$, número de perfilhos. Palmital, SP, 2006/07 e 2007/08.

\begin{tabular}{|c|c|c|c|c|}
\hline \multicolumn{5}{|c|}{$2006 / 07$} \\
\hline Cultivar & $\begin{array}{c}\text { Circunferência do } \\
\text { pseudocaule (m) }\end{array}$ & $\begin{array}{c}\mathrm{N}^{0} \text { de folhas vivas no } \\
\text { florescimento }\end{array}$ & $\begin{array}{l}\text { Altura de planta } \\
\text { (m) }\end{array}$ & $N^{0}$ de perfilhos \\
\hline Nanicão IAC 2001 & $0,66 \mathrm{a}$ & $10,5 \mathrm{a}$ & $2,00 \mathrm{~b}$ & $3,6 \mathrm{~b}$ \\
\hline Nanicão Jangada & $0,57 \mathrm{~b}$ & $11,2 \mathrm{a}$ & $1,72 \mathrm{c}$ & $3,3 \mathrm{~b}$ \\
\hline Grande Naine & $0,66 \mathrm{a}$ & $10,5 \mathrm{a}$ & $2,03 \mathrm{~b}$ & $5,7 \mathrm{a}$ \\
\hline Caipira & $0,47 \mathrm{c}$ & $9,2 \mathrm{~b}$ & $1,54 \mathrm{~d}$ & $5,6 \mathrm{a}$ \\
\hline Thap Maeo & $0,58 \mathrm{~b}$ & $10,2 \mathrm{~b}$ & $2,03 \mathrm{~b}$ & $5,5 \mathrm{a}$ \\
\hline Preciosa & $0,68 \mathrm{a}$ & $9,9 \mathrm{~b}$ & $2,57 \mathrm{a}$ & $4,2 \mathrm{~b}$ \\
\hline Maravilha & $0,68 \mathrm{a}$ & $10,3 \mathrm{~b}$ & $1,88 \mathrm{~b}$ & $3,7 \mathrm{~b}$ \\
\hline PV4253 & $0,69 \mathrm{a}$ & $10,7 \mathrm{a}$ & $2,72 \mathrm{a}$ & $3,8 \mathrm{~b}$ \\
\hline CV (\%) & 7,74 & 9,04 & 8,74 & 20,41 \\
\hline \multicolumn{5}{|c|}{$2007 / 08$} \\
\hline Cultivar & $\begin{array}{c}\text { Circunferência do } \\
\text { pseudocaule (m) }\end{array}$ & $\begin{array}{c}\mathrm{N}^{0} \text { de folhas vivas na } \\
\text { colheita }\end{array}$ & $\begin{array}{l}\text { Altura de planta } \\
(\mathrm{m})\end{array}$ & $N^{0}$ de perfilhos \\
\hline Nanicão IAC 2001 & $0,65 \mathrm{~b}$ & $5,0 \mathrm{a}$ & $2,56 \mathrm{~b}$ & $5,3 \mathrm{~d}$ \\
\hline Nanicão Jangada & $0,62 \mathrm{~b}$ & $4,2 \mathrm{~b}$ & $2,67 \mathrm{~b}$ & $5,6 \mathrm{~d}$ \\
\hline Grande Naine & $0,64 \mathrm{~b}$ & $4,4 \mathrm{~b}$ & $2,48 \mathrm{~b}$ & $6,9 \mathrm{c}$ \\
\hline Caipira & $0,52 \mathrm{c}$ & $4,4 \mathrm{~b}$ & $2,58 \mathrm{~b}$ & $9,9 \mathrm{a}$ \\
\hline Thap Maeo & $0,57 \mathrm{c}$ & $5,0 \mathrm{a}$ & $2,71 \mathrm{~b}$ & $8,4 \mathrm{~b}$ \\
\hline Preciosa & $0,63 \mathrm{~b}$ & $4,4 \mathrm{~b}$ & $3,02 \mathrm{a}$ & $7,4 \mathrm{c}$ \\
\hline Maravilha & $0,76 \mathrm{a}$ & $6,0 \mathrm{a}$ & $2,83 \mathrm{a}$ & $6,0 \mathrm{~d}$ \\
\hline PV4253 & $0,66 \mathrm{~b}$ & $5,4 \mathrm{a}$ & $3,11 \mathrm{a}$ & $7,0 \mathrm{c}$ \\
\hline CV (\%) & 6,01 & 14,07 & 9,68 & 11,03 \\
\hline
\end{tabular}

Médias seguidas da mesma letra, na coluna, não diferem entre si, pelo teste de Scott-Knott a 5\% de probalidade.

Fonte: Elaboração dos autores. 
O número de folhas vivas no florescimento, avaliado no ano 2006/07, variou de 9,2 a 11,2 folhas entre as cultivares e no ciclo 2007/08, variou de 4,2 a 6,0. O caráter número de folhas na floração é um descritor importante na avaliação de genótipos, uma vez que tem influência direta no desenvolvimento do cacho (SOTO BALLESTERO, 1992). Neste experimento, a cultivar Nanicão IAC 2001, e o genótipo PV4253 mantiveram-se como as plantas com maior valor para este parâmetro, enquanto as cultivares Caipira e Preciosa mantiveram-se no grupo com menor desenvolvimento, mostrando que o desempenho destas foi pouco influenciado pelas condições da região do Médio Paranapanema. Já as cultivares Thap Maeo e Maravilha apresentaram mais folhas vivas no segundo ciclo, sugerindo que as condições edafoclimáticas beneficiaram estas variedades e no sentido inverso, as cultivares Nanicão Jangada, Grande Naine e Maravilha que apresentaram menor número de folhas vivas no ciclo de 2007/08.

Esta característica também está relacionada ao grau de resistência de um genótipo à Sigatoka. Oliveira et al. (1993), avaliando a cultivar PrataAnã e seus híbridos resistentes à Sigatoka Amarela, observaram que estes últimos estavam com número de folhas funcionais na floração considerado satisfatório (acima de 10) e capaz de permitir à planta um bom desenvolvimento do cacho. Na colheita, o número de folhas vivas nos híbridos resistentes era praticamente o dobro do genótipo não resistente Prata-Anã, demonstrando que nos híbridos somente ocorreu morte natural das folhas por senescência, enquanto na variedade Prata-Anã a morte mais rápida das folhas foi associada ao ataque da Sigatoka.

Tão importante quanto um número adequado de folhas no momento da floração, é que a planta consiga manter as folhas durante o período de enchimento dos frutos, já que não há emissão foliar após a floração (RODRIGUES; SOUTO; SILVA, 2006). Silva et al. (2006) comentam que a redução do número de folhas da floração até a colheita pode ocorrer também pela translocação de fotoassimilados para a formação de frutos e à senescência natural das folhas, além da perda de folhas por Sigatoka.

A altura das plantas no ciclo 2006/07 foi de 1,54 a 2,72 m. No ciclo 2007/08 houve amplitude de 2,48 a 3,11 m. Njuguna et al. (2008) observaram que o genótipo mais alto não apresenta, necessariamente, mais folhas que os genótipos mais baixos, fato esse também observado no presente trabalho. Também foi observado por esses autores que a produtividade não depende apenas da altura de planta e do número de folhas funcionais ou totais no florescimento, mas também de outros fatores, principalmente os genéticos. Além disso, plantas menores apresentam a vantagem de serem menos suscetíveis ao tombamento por vento (SÔNEGO; PERUCH; LICHTEMBERG, 2007).

Quanto ao número de perfilhos, as cultivares que apresentaram os maiores valores para este parâmetro em um ano não foram necessariamente as mesmas que apresentaram os maiores números de perfilhos no ano seguinte. No ano 2006/07, o número de perfilhos variou de 3,3 para a cultivar Nanicão Jangada até 5,7 perfilhos para Grande Naine. No ano de 2007/08, este parâmetro variou de 5,3 para a cultivar Nanicão IAC 2001 até 9,9 perfilhos para Caipira. O número de perfilhos do ano 2006/07 para o ano 2007/08 foi acumulativo, já que não ocorreu desbaste. Nesse sentido, apenas a cultivar Caipira manteve a característica de ser a que mais emite perfilhos, enquanto todas as outras diminuíram o perfilhamento no segundo ano.

Quanto aos caracteres de produção (Tabela 2), as cultivares Nanicão Jangada, Grande Naine e Nanicão IAC 2001 apresentaram maior massa de cacho, com valores de 17,60, 16,43 e 15,98 kg, respectivamente. As cultivares Maravilha e PV4253 apresentaram médias um pouco menores, com 14,02 e $13,80 \mathrm{~kg}$, respectivamente. Enquanto as cultivares Thap Maeo, Preciosa e Caipira apresentaram as menores médias de massa de cacho, com 10,73; 9,85 e $9,50 \mathrm{~kg}$, respectivamente. Esses resultados estão em concordância com os observado no primeiro 
ciclo para os genótipos Grande Naine, Caipira e Thap Maeo, por Silva, Flores e Lima Neto (2002), em condições de irrigação em Cruz das Almas (BA). Porém, nas três safras seguintes daquele trabalho, apesar da cultivar Grande Naine ter repetido o desempenho da primeira safra, Caipira e Thap Maeo tiveram cachos bem mais pesados, com 16,3 a 21,3 kg para Caipira e de 15,1 a 29,3 kg para Thap Maeo.

Tabela 2. Médias de massa do cacho $(\mathrm{kg})$, massa do engaço $(\mathrm{kg})$, massa das pencas $(\mathrm{kg})$, massa da $2^{\mathrm{a}}$ penca $(\mathrm{kg})$ e número de pencas/cacho. Palmital, SP, 2007/08.

\begin{tabular}{cccccc}
\hline Cultivares & $\begin{array}{c}\text { Massa do } \\
\text { cacho }(\mathbf{k g})\end{array}$ & $\begin{array}{c}\text { Massa do } \\
\text { engaço (kg) }\end{array}$ & $\begin{array}{c}\text { Massa das } \\
\text { pencas (kg) }\end{array}$ & $\begin{array}{c}\text { Massa da 2 }^{\mathbf{a}} \\
\text { penca (kg) }\end{array}$ & $\begin{array}{c}\text { Número de } \\
\text { pencas/cacho }\end{array}$ \\
\hline Nanicão IAC 2001 & $15,98 \mathrm{a}$ & $1,20 \mathrm{a}$ & $14,78 \mathrm{a}$ & $2,25 \mathrm{a}$ & $8,3 \mathrm{a}$ \\
Nanicão Jangada & $17,60 \mathrm{a}$ & $1,28 \mathrm{a}$ & $16,32 \mathrm{a}$ & $2,46 \mathrm{a}$ & $8,3 \mathrm{a}$ \\
Grande Naine & $16,43 \mathrm{a}$ & $1,18 \mathrm{a}$ & $15,25 \mathrm{a}$ & $2,41 \mathrm{a}$ & $7,4 \mathrm{a}$ \\
Caipira & $9,50 \mathrm{c}$ & $0,84 \mathrm{~b}$ & $8,66 \mathrm{c}$ & $1,57 \mathrm{c}$ & $6,7 \mathrm{~b}$ \\
Thap Maeo & $10,73 \mathrm{c}$ & $0,86 \mathrm{~b}$ & $9,87 \mathrm{c}$ & $1,29 \mathrm{c}$ & $8,1 \mathrm{a}$ \\
Preciosa & $9,85 \mathrm{c}$ & $0,81 \mathrm{~b}$ & $9,04 \mathrm{c}$ & $1,42 \mathrm{c}$ & $6,0 \mathrm{~b}$ \\
Maravilha & $14,02 \mathrm{~b}$ & $1,22 \mathrm{a}$ & $12,79 \mathrm{~b}$ & $1,97 \mathrm{~b}$ & $8,5 \mathrm{a}$ \\
PV4253 & $13,80 \mathrm{~b}$ & $1,20 \mathrm{a}$ & $12,60 \mathrm{~b}$ & $2,33 \mathrm{a}$ & $6,5 \mathrm{~b}$ \\
\hline CV (\%) & 10,13 & 10,70 & 10,46 & 9,67 & 9,57 \\
\hline
\end{tabular}

Médias seguidas da mesma letra, na coluna, não diferem entre si, pelo teste de Scott-Knott a 5\% de probalidade.

Fonte: Elaboração dos autores.

Esses resultados de produção apresentados no presente estudo foram prejudicados pelas condições climáticas, uma vez que o experimento não foi irrigado e a ocorrência de chuva na região foi irregular e atípica, com valores abaixo do indicado por Moreira (1999) de $100 \mathrm{~mm}$ mensais, nos meses de outubro e novembro de 2006, março, abril, setembro e outubro de 2007 e fevereiro e março de 2008 (Figura 1).

Para massa do engaço, foram observados dois grupos: os maiores valores foram observados nas cultivares Nanicão Jangada, Maravilha, Nanicão IAC 2001, PV4253 e Grande Naine com médias entre 1,28 a $1,18 \mathrm{~kg}$; o segundo grupo foi formado pelas cultivares Thap Maeo, Caipira e Preciosa com médias entre 0,86 a $0,81 \mathrm{~kg}$.

Já para massa da segunda penca foram observados três grupos entre as cultivares, compostos pelas cultivares Nanicão Jangada, Grande Naine, PV4253 e Nanicão IAC 2001 com variação de 2,46 a 2,25 $\mathrm{kg}$ penca $^{-1}$, seguidas pela cultivar Maravilha com $1,97 \mathrm{~kg}$ penca $^{-1}$ e pelo terceiro grupo formado pelas cultivares Caipira, Preciosa e Thap Maeo com variação de 1,57 a 1,29 kg penca-1. De acordo com Soto-Ballestero (1992), a massa da segunda penca está relacionada a várias características importantes das cultivares como o ponto de colheita ideal, a massa média dos frutos, comprimento e diâmetro dos frutos, além de composição química como sólidos totais e brix; esses parâmetros são fundamentais para a aceitação das frutas pelo mercado consumidor.

Para o número de pencas por cacho foram obervados dois grupos entre as cultivares. As cultivares Maravilha, Nanicão IAC 2001, Nanicão Jangada, Thap Maeo e Grande Naine formaram o primeiro grupo com variação de 8,5 a 7,4 pencas cacho $^{-1}$; as cultivares Caipira, PV 4253 e Preciosa apresentaram o menor número de pencas por cacho com variação entre 6,7 a 6,0 pencas cacho ${ }^{-1}$. A massa da segunda penca e o número de pencas por cacho apresentaram comportamento similar ao da massa do cacho, exceto para a cultivar Thap Maeo.

O número de pencas por cacho é importante para o produtor uma vez que o aumento no número de pencas acarreta em aumento no número de frutos e conseqüentemente, aumenta a massa do cacho (SILVA et al., 2006). No entanto, neste experimento, 
apesar do elevado número de pencas por cacho da cultivar Thap Maeo, estas, incluindo-se a $2^{\mathrm{a}}$ penca, eram menores e mais leves, discordando da observação realizada por Silva et al. (2006).

O número de frutos por cacho e número de frutos por penca foi menor para a cultivar Preciosa e o número de frutos por penca e número de frutos da segunda penca foram maiores para as cultivares Nanicão Jangada e Caipira (Tabela 3). Esta característica da Nanicão Jangada, aliada ao fato de que é a variedade com menor espessura de casca, mostrou que nas condições de Palmital, esta foi a cultivar com maior massa de frutos, o quê pode ser um característica importante se o intuito do produtor for comercializar a polpa do fruto para a indústria.

Tabela 3. Médias de número de frutos/cacho, número de frutos/penca, número de frutos da $2^{\mathrm{a}}$ penca, diâmetro externo de frutos da $2^{\mathrm{a}}$ penca $(\mathrm{mm})$, espessura da casca $(\mathrm{mm})$, comprimento de fruto $(\mathrm{cm})$ e massa do fruto mediano da $2^{\mathrm{a}}$ penca (g). Palmital, SP, 2007/08.

\begin{tabular}{cccccccc}
\hline Cultivares & $\begin{array}{c}\text { frutos } \\
\text { cacho }^{-1}\end{array}$ & $\begin{array}{c}\text { frutos } \\
\text { penca }^{-1}\end{array}$ & $\begin{array}{c}\text { frutos } \\
\mathbf{2}^{\mathbf{a}} \\
\text { penca }\end{array}$ & $\begin{array}{c}\text { diâmetro } \\
\text { externo } \\
\text { (mm) }\end{array}$ & $\begin{array}{c}\text { espessura } \\
\text { de casca } \\
(\mathbf{m m})\end{array}$ & $\begin{array}{c}\text { comprimento } \\
(\mathbf{c m})\end{array}$ & $\begin{array}{c}\text { Massa do } \\
\text { fruto (g) }\end{array}$ \\
\hline Nanicão IAC 2001 & $116,0 \mathrm{a}$ & $13,9 \mathrm{~b}$ & $15,2 \mathrm{~b}$ & $28,50 \mathrm{a}$ & $3,98 \mathrm{a}$ & $19,73 \mathrm{~b}$ & $140,68 \mathrm{a}$ \\
Nanicão Jangada & $131,2 \mathrm{a}$ & $15,8 \mathrm{a}$ & $18,0 \mathrm{a}$ & $30,20 \mathrm{a}$ & $2,98 \mathrm{c}$ & $21,42 \mathrm{a}$ & $149,27 \mathrm{a}$ \\
Grande Naine & $109,9 \mathrm{a}$ & $14,9 \mathrm{~b}$ & $15,8 \mathrm{~b}$ & $29,78 \mathrm{a}$ & $3,27 \mathrm{~b}$ & $20,35 \mathrm{~b}$ & $144,32 \mathrm{a}$ \\
Caipira & $108,7 \mathrm{a}$ & $16,2 \mathrm{a}$ & $18,7 \mathrm{a}$ & $28,93 \mathrm{a}$ & $1,87 \mathrm{e}$ & $14,77 \mathrm{e}$ & $87,66 \mathrm{~d}$ \\
Thap Maeo & $116,9 \mathrm{a}$ & $14,5 \mathrm{~b}$ & $15,6 \mathrm{~b}$ & $29,83 \mathrm{a}$ & $2,38 \mathrm{~d}$ & $13,81 \mathrm{f}$ & $91,05 \mathrm{~d}$ \\
Preciosa & $69,8 \mathrm{c}$ & $11,7 \mathrm{~d}$ & $12,6 \mathrm{c}$ & $25,02 \mathrm{c}$ & $3,48 \mathrm{~b}$ & $15,87 \mathrm{~d}$ & $105,81 \mathrm{c}$ \\
Maravilha & $113,6 \mathrm{a}$ & $13,3 \mathrm{c}$ & $14,8 \mathrm{~b}$ & $27,45 \mathrm{~b}$ & $3,05 \mathrm{c}$ & $17,42 \mathrm{c}$ & $114,47 \mathrm{~b}$ \\
PV4253 & $92,4 \mathrm{~b}$ & $14,2 \mathrm{~b}$ & $15,4 \mathrm{~b}$ & $29,10 \mathrm{a}$ & $2,43 \mathrm{~d}$ & $17,63 \mathrm{c}$ & $114,44 \mathrm{~b}$ \\
\hline CV (\%) & 10,93 & 4,41 & 6,84 & 3,49 & 5,10 & 2,64 & 4,66 \\
\hline
\end{tabular}

Médias seguidas da mesma letra, na coluna, não diferem entre si, pelo teste de Scott-Knott a 5\% de probalidade.

Fonte: Elaboração dos autores.

A cultivar Nanicão Jangada apresentou frutos com maior diâmetro e a cultivar Preciosa apresentou frutos de menor diâmetro, e isso se refletiu diretamente nas características comprimento e massa do fruto que mantiveram esta tendência.

A cultivar Nanicão IAC 2001 foi a que apresentou maior espessura de casca, enquanto que a cultivar Caipira apresentou os menores valores para este parâmetro. A espessura da casca influencia no rendimento líquido do fruto e é importante componente de resistência ao transporte (RODRIGUES; SOUTO; SILVA, 2006).

O comprimento do fruto da segunda penca apresentou variação entre quase todas as cultivares, sendo que a cultivar Thap Maeo apresentou frutos de menor comprimento, no entanto, algumas cultivares como a Nanicão IAC 2001 e a Grande Naine, mesmo não sendo as com maior comprimento de frutos, produziram bananas mais pesadas que não diferiram da massa dos frutos da cultivar Nanicão Jangada.

A massa do fruto da segunda penca também foi maior para as cultivares do grupo Cavendish e as cultivares Caipira e Thap Maeo foram as que apresentaram as menores médias de massa de fruto da segunda penca.

\section{Conclusões}

Os genótipos do subgrupo Cavendish apresentaram melhor comportamento vegetativo e produtivo, com destaque para a cultivar Nanicão Jangada que apresentou melhor comportamento para a maioria dos caracteres de produção avaliados, sendo indicada para plantio na região.

Ascultivares Prata Zulue Thap Maeoapresentaram 
comportamento semelhante a Nanicão IAC 2001, cultivada na região, e são alternativas de cultivo, uma vez que apresentam resistência às sigatokas amarela e negra, principais doenças da cultura.

Os genótipos Maravilha e PV 4253 apresentaramse promissores para a região e necessitam ser avaliados em ciclos posteriores.

\section{Agradecimentos}

Os autores agradecem à Empresa Brasileira de Pesquisa Agropecuária, unidade EMBRAPA Mandioca e Fruticultura Tropical, de Cruz das Almas, Bahia e ao "Laboratório de Cultivo in vitro de Espécies Ornamentais e Frutíferas" da ADRBiomavale, Assis, São Paulo, pela cessão das mudas de bananeiras micropropagadas utilizadas neste experimento. Agradecem também aos Irmãos Bernardes - Produção embalagem e transporte de frutas, na pessoa de Edelberto Bernardes, pela cessão da área para instalação do experimento.

\section{Referências}

AGRIANUAL 2011. Anuário da agricultura brasileira. São Paulo: FNP, 2011. p. 168-180.

CENTRO INTEGRADO DE INFORMAÇÕES AGROMETEOROLÓGICAS - CIIAGRO. Instituto Agronômico de Campinas, IAC. 2011. Disponível em: $<$ http://www.ciiagro.sp.gov.br>. Acesso em: 15 jun. 2011.

CORDEIRO, Z. J. M.; MATOS, A. P. Doenças fúngicas e bacterianas. In: CORDEIRO, Z. J. M. Banana: fitossanidade. Cruz das Almas: EMBRAPA Mandioca e Fruticultura, 2000a. p. 36-65.

Doenças. In: CORDEIRO, Z. J. M. Banana: produção. Brasília: EMBRAPA, 2000b. p. 106-117.

DONATO, S. L. R.; SILVA, S. O.; LUCCA FILHO, O. A.; LIMA, M. B.; DOMINGUES, H.; ALVES, J. S. Correlação entre caracteres da planta e do cacho em bananeira (Musa spp). Ciência e Agrotecnologia, Lavras, v. 30, n. 1, p. 21-30, 2006.

FURLANETO, F .P. B.; MARTINS, A. N.; CAMOLESI, M. R.; ESPERANCINI, M. S. T. Análise econômica de sistemas de produção de banana (Musa sp.), cv. Grande Naine, na região do Médio Paranapanema, estado de São Paulo. Revista Cientifica, Jaboticabal, v. 35, n. 2, p. 188195, 2007.
FURLANETO, F. P. B.; MARTINS, A. N.; GOLDONI, C. L.; ESPERANCINI, M. S. T. Custo de produção e rentabilidade da banana "maçã" (Musa spp.) na região do Médio Paranapanema, Estado de São Paulo, 2005. Revista Informações Econômicas, São Paulo, v. 35, n. 12, p. 19-25, 2005.

LEDO, A. S.; SILVA JUNIOR, J. F.; LEDO, C. A. S.; SILVA, S. O. Avaliação de genótipos de bananeira na região do baixo São Francisco, Sergipe. Revista Brasileira de Fruticultura, Jaboticabal, v. 30, n. 3, p. 691-695, 2008.

MOREIRA, R. S. Banana-teoria e prática de cultivo. 2. ed. São Paulo: Fundação Cargill, 1999.

NJUGUNA, J.; NGUTHI, F.; WEPUKHULU, S.; GITAU, D.; KARUOYA, M.; KARAMURA, D. Introduction and evaluation of improved banana cultivars for agronomic and yield characteristics in Kenia. African Crop Science Journal, Uganda, v. 16, n. 1, p. 35-40, 2008.

OLIVEIRA, M. A.; ALVES, E. J.; SHEPHERD, K.; SOARES FILHO, W. S.; CORDEIRO, Z. J. M.; DANTAS, J. L. L.; SILVA, S. O. Avaliação agronômica de cultivares e híbridos promissores de banana: I - Porte médio. Revista Brasileira de Fruticultura, Cruz das Almas, v. 15, n. 3, p. 7-13, 1993.

OLIVEIRA, T. K.; LESSA, L. S.; SILVA, S. O.; OLIVEIRA, J. P. Características agronômicas de genótipos de bananeira em três ciclos de produção em Rio Branco-AC. Pesquisa Agropecuária Brasileira, Brasília, v. 43, n. 8, p. 1003-1010, 2008.

RODRIGUES, M. G. V.; SOUTO, R. F.; SILVA, S. de $\mathrm{O}$. Avaliação de genótipos de bananeira sob irrigação. Revista Brasileira de Fruticultura, Jaboticabal, v. 28, n. 3, p. 444-448, 2006.

SILVA, S. de O.; FLORES, J. C. de O.; LIMA NETO, F. P. Avaliação de cultivares e híbridos de bananeira em quatro ciclos de produção. Pesquisa Agropecuária Brasileira, Brasília, v. 37, n. 11, p. 1567-1574, 2002.

SILVA, S. O.; PIRES, E. T.; PESTANA, R. K. N.; ALVES, J. S.; SILVEIRA, D. C. Avaliação de clones de banana Cavendish. Ciência e Agrotecnologia, Lavras, v. 30 , n. 5, p. 832-837, 2006

SÔNEGO, M.; PERUCH, L. A. M.; LICHTEMBERG, L. A. Danos do furacão Catarina em bananeiras sob cultivo orgânico no sul de Santa Catarina. Revista Brasileira de Agroecologia, v. 2, n. 1, p. 1210-1213, 2007.

SOTO-BALLESTERO, M. Bananos: cultivo y comercialización. 2. ed. SanJosé: Litografía e Imprenta Lil, 1992. 674 p. 